\title{
O circo e a educação dos corpos-criança: possibilidades formativas com espaço para o pensar e o fazer divergente
}

\author{
The circus and the education of child-bodies: formative possibilities \\ with space for divergent thinking and doing
}

\section{El circo y la educación del cuerpo infantil: posibilidades formativas con espacio para el pensar y el hacer divergente}

\author{
Aliandra Cristina Mesomo Lira 1 \\ https://orcid.org/0000-0003-2945-464X \\ Gláucia Andreza Kronbauer ${ }^{2}$ \\ https://orcid.org/0000-0003-2338-7685
}

\begin{abstract}
Resumo: Este artigo tem o objetivo de discutir o potencial educativo dos corpos circenses e da linguagem artística a eles inerente, e sua contribuição na constituição de corpos-criança que têm direito de se movimentar, expressar seus desejos e desencantos, de questionar e fruir corporalmente a vida. Pautamo-nos no diálogo entre a literatura acadêmica e os relatos do projeto de extensão "Circo em Contexto", por meio de pesquisa bibliográfica e análise documental de relatório do projeto. O projeto é desenvolvido na Universidade Estadual do Centro-Oeste, campus Irati, Paraná e oferece oficinas de práticas corporais circenses para crianças de 4 a 12 anos de idade. Os resultados indicam a experiência com as práticas corporais circenses como uma possibilidade de dar vida e lugar ao corpo-criança, sendo um espaço-tempo formativo que acolhe o pensar e o fazer divergentes ao privilegiar ações que acionam a imaginação, a criatividade e a coletividade.
\end{abstract}

Palavras-chave: Circo. Infância. Educação. Corpo.

\begin{abstract}
The article aims to discuss the educational potential of circus bodies and the artistic language inherent in them, and their contribution to the constitution of child-bodies that have the right to move, to express their desires and disenchantments, to question, and to bodily enjoy life. We are guided by the dialogue between academic literature and the accounts of the extension project 'Circus in Context', by means of bibliographic research and documental analysis of the project report. The Project is developed at the Universidade Estadual do Centro-Oeste, at Irati campus, in Paraná, and offers circus body practices workshops to children from 4 to

\footnotetext{
' Doutora em Educação pela Universidade de São Paulo (USP). Professora do Departamento de Pedagogia e do Programa de Pós-Graduação em Educação da Universidade Estadual do Centro-Oeste (UNICENTRO). E-mail: aliandralira@gmail.com

${ }^{2}$ Doutora em Educação pela Universidade Estadual de Ponta Grossa (UEPG). Professora do Departamento de Educação Física e do Programa de Pós-Graduação em Educação da Universidade Estadual do Centro-Oeste (UNICENTRO). E-mail: glaucia.kronbauer@gmail.com
} 
12 years old. The results indicate the experience with circus body practices as a possibility of giving life and place to the child-body, being a formative space-time that hosts divergent thinking and doing by privileging actions that activate imagination, creativity, and collectivity.

Keywords: Circus. Childhood. Education. Body.

Resumen: El objetivo de esta investigación es discutir el potencial educativo de los cuerpos circenses y el lenguaje artístico que les es inherente, y su contribución a la constitución de cuerpos infantiles que tienen derecho a moverse, expresar sus deseos y desencantos, cuestionar y disfrutar de la vida corporalmente. Nos guía el diálogo entre la literatura académica y los relatos del proyecto de extensión 'El Circo en Contextos', a través de la investigación bibliográfica y el análisis documental del informe del proyecto. El proyecto se desarrolla en la Universidade Estadual do Centro-Oeste - UNICENTRO (Universidad Estatal del Medio Oeste), Unidad de Irati, Paraná, y ofrece talleres sobre prácticas corporales circenses para niños de 4 a 12 años de edad. Los resultados apuntan la experiencia con prácticas corporales circenses como posibilidad de dar vida y lugar al cuerpo infantil, siendo un espacio-tiempo formativo que acoge el pensamiento y el hacer divergentes privilegiando acciones que accionan la imaginación, la creatividad y la colectividad.

Palabras-clave: Circo. Infancia. Educación. Cuerpo.

\section{Introdução}

Cores e luminosidades, sons e odores, texturas e sabores, vão compondo em nós saberes que nos enraízam no mundo, pois são por nós incorporados como sentidos que nos situam em nossa história. Aqui, não represento o mundo, estou nele. Reparar o mundo restaura uma linguagem atenta às qualidades da vida, exige sensualidade atenta para aprender a tocá-lo como ele nos toca, a intensificar sentidos que deslocam meu corpo e me instalam no mundo. Exige do corpo experiência estética da lentidão que potencializa a atenção aos detalhes, essas pequenas e ínfimas alegrias que emergem do encontro do corpo com o mundo, outra temporalidade no modo de apreciar a inteligibilidade inerente à qualidade das coisas, outro tempo em mim. Implica compreender que vamos nos tornando na simultaneidade que o mundo torna-se para nós e os outros.

(RICHTER, 2016, p. 98-99).

Escolhemos esta citação para iniciar nosso artigo, pois acreditamos que ela nos mobiliza a pensar sobre a existência corporal, o ser corpo e as formas como aprendermos e construímos nossa humanidade por meio de relações sensíveis com o mundo. Esses saberes necessitam de afeto, de intensidade, de tempo; este que, por vezes, não condiz com as exigências de produtividade e funcionalidade dos processos educativos contemporâneos.

Há alguns anos, mas ainda atual, Isabel Marques chamava a atenção para a sobrevalorização do conhecimento "[...] analítico, descritivo e linear em detrimento do conhecimento sintético, sistêmico, corporal, intuitivo [...]”, característica das sociedades modernas (MARQUES, 2003, p. 18). O diálogo entre os autores possibilita problematizar a nossa condição corporal em contradição com a hierarquia de valores associados às diferentes formas e linguagens de conhecer e, consequentemente, de ser, agir e interagir em sociedade. Já cantava Oswaldo Montenegro (1980):

Se você dançar a noite inteira não significa dar bobeira De manhã se alienar ou esquecer É a busca do supremo equilíbrio num processo inteligente 
Com base na letra da música, quer traz à baila a relação entre o pensar e o dançar, tematizamos o circo e, mais especificamente, as práticas corporais circenses, como possibilidade de ampliar e diversificar as experiências corporais na infância e estimular os saberes sensíveis. O circo é uma manifestação cultural que perpassa as sociedades ao longo da história e suas técnicas não são exclusivas da lona. Podemos assumir que há o circo institucionalizado, que surge na Europa acompanhando os movimentos de industrialização nos séculos XVIII e XIX e percorre o mundo desde então, estabelecendo diálogo e assimilando aspectos contemporâneos aos contextos sociais e culturais em que se estrutura (BOLOGNESI, 2009). Há, por outro lado, a linguagem circense, cujas manifestações ocupam rituais, festividades regionais e praças públicas desde os primeiros grupos humanos (SILVA, 2003). Esta última tem no corpo seu principal artista, que expressa elementos diversos e assume distintos significados nos tempos e espaços em que se manifesta (BOLOGNESI, 200I). Trataremos aqui, das práticas corporais circenses como expressões artísticas que envolvem o universo do circo, mas se manifestam para além dos limites da lona, em espaços educativos e de lazer.

Referimo-nos ao corpo como síntese dialética entre natureza e consciência, como instrumento de expressão da vida, como materialidade da existência. Partimos do princípio de que o corpo é o nosso meio de relação com o ambiente; pelos sentidos experimentamos o mundo e constituímos nossa consciência e existência. Por isso mesmo, em vez de estabelecer uma relação de afastamento e propriedade de um corpo-objeto que pertence a um sujeito, o entendimento é de uma relação de identidade, de corpo que é sujeito e sujeito que é corpo. Novamente, recorremos à música para expressar essa compreensão:

E bate louco, bate criminosamente, o coração mais do que a mente Bate o pé mais do que o corpo poderia $E$ se você mentalizasse na folia, sabe lá se não seria a solução Pra de manhã pensar melhor $E$ caso fosse $a$ incompatibilidade entre o corpo e consciência Iria desaparecer, você não vê Como o corpo preparado pode ser iluminado Como a luz de uma fogueira que precisa se manter 4

O sociólogo e antropólogo Marcel Mauss (2003) nomeou de "técnicas corporais" as formas com as quais os seres humanos, em diferentes tempos e espaços da história, valeram-se de seus corpos. Isso significa que as ações corporais, ainda que resultantes de processos físico-biológicos, são

\footnotetext{
3 Música "Incompatibilidade", de Oswaldo Montenegro, lançada em 1980, no álbum Oswaldo Montenegro [Oswaldo Montenegro].

4 Música "Incompatibilidade", de Oswaldo Montenegro, lançada em 1980, no álbum "Oswaldo Montenegro" [Oswaldo Montenegro].
} 
condicionadas por histórias de vida e contextos coletivos, ou seja, cada grupo social, e cada sujeito deste grupo, constrói formas próprias de se movimentar, com significados singulares e mediadas pela cultura. Esse processo acontece desde o início da vida e se caracteriza pela impossibilidade de conclusão, isto é, desde a infância até a morte estamos constantemente construindo maneiras de ser corpo no mundo.

Fundamentadas por essa perspectiva, assumimos como educação os diferentes processos que nos dão acesso à cultura historicamente elaborada pela humanidade, quer dizer, que nos constituem como membros da espécie humana. Assim, nem toda a educação, e especificamente a educação do corpo (HEROLD JR., 20I2), é um ato intencional e consciente e, por vezes, ela acontece nas relações cotidianas e nas mais diversas atividades humanas, por meio da observação e da imitação do outro.

Entre essas, podemos citar a atividade artística como espaço privilegiado de educação. Amplos são os debates sobre a função das expressões artísticas em uma sociedade. Por um lado, há quem defenda que a arte tem um fim em si mesma, que sua função é ser arte, pura contemplação; por outro, há quem concentre esforços em justificar a funcionalidade da arte como distração, ou como educação, ou como instrumento de conscientização, entre outras possibilidades.

Neste texto partimos do pressuposto de que esses aspectos não são excludentes, mas estão todos incorporados em uma obra (PAREYSON, 200I). Isso significa que a função educativa de uma determinada manifestação artística, como o circo, por exemplo, não descaracteriza seu valor estético.

Cabe também registrar, de início, nossa compreensão de que a arte e todos os processos artísticos podem representar a oportunidade de alimentar o pensar e o fazer divergente, ou seja, desde que não se resumam a cópias, imitações, produções iguais e convergentes, mas sim acolham e oportunizem a diversidade, a criação, sendo avessos ao convencional. Outro aspecto a ser esclarecido, a partir de Santos e Lira (2020), é que quando falamos de corpo-criança estamos nos referindo à alegria, movimento, audácia, à vida de corpo inteiro, diferenciando-o do corpo-aluno, formatado pela lógica escolar que constrange, limita e controla movimentos e comportamentos.

A partir dos encontros e desencontros entre a educação, a arte e as práticas corporais na infância, este texto tem $\circ$ objetivo de discutir o potencial educativo dos corpos circenses e da linguagem artística a eles inerente, e sua contribuição na constituição de corpos-criança que têm direito de se movimentar, expressar seus desejos e desencantos, de questionar e fruir corporalmente a vida.

Pautamo-nos no diálogo entre a literatura acadêmica e os relatos das atividades do projeto de extensão "Circo em Contextos"5, desenvolvido na Universidade Estadual do Centro-Oeste, campus Irati, PR, que buscou fomentar as possibilidades de experimentações corporais na infância.

\footnotetext{
5 O projeto mencionado no texto recebeu financiamento da Superintendência de Ciência, Tecnologia e Ensino Superior do Estado do Paraná, por meio do Programa Universidade Sem Fronteiras.
} 
Apresentamos, incialmente, os fundamentos conceituais das nossas discussões, a partir de pesquisa bibliográfica e, em seguida, análise dos dados de relatório do referido projeto.

\title{
Infância, práticas corporais artísticas e processos criativos
}

Ao longo da história, as práticas corporais e as expressões artísticas caminharam lado a lado, em relações de complementariedade e retroalimentação. Tais manifestações encontram-se representadas nas práticas corporais rítmicas, no circo e na mímica e, como dissemos, atuam na constituição dos sujeitos ao longo da vida. De modo especial, podemos destacar a estreita relação entre a educação, as práticas artísticas e a infância.

Richter, Silva e Faria $(2017$, p. 238) ressaltam que "A importância das primeiras aprendizagens está na emergência do complexo processo de aprender a desvendar os segredos das linguagens ao arranjar e rearranjar o real pela intensidade narrativa de um corpo 'encenando' o mundo". Assim, arte e educação firmam uma cumplicidade de muitos aprendizados, estão diretamente implicadas na humanização.

Veiga-Neto (2003) discute a dimensão pluralista das formas de vida e pensamento e o papel da cultura na estruturação dos comportamentos individuais e coletivos na humanização. $O$ autor destaca que a diversidade dos modos de vida e crenças humanas orienta nosso agir e pensar, ou seja, não nascemos prontos, mas nos constituímos; compartilhando, assim, da compreensão de Hall (1997, p. 16):

\begin{abstract}
Os seres humanos são seres interpretativos, instituidores de sentido. A ação social é significativa tanto para aqueles que a praticam quanto para os que a observam: não em si mesma, mas em razão dos muitos e variados sistemas de significado que os seres humanos utilizam para definir o que significam as coisas e para codificar, organizar e regular sua conduta uns em relação aos outros. Estes sistemas ou códigos de significado dão sentido às nossas ações. Eles nos permitem interpretar significativamente as ações alheias. Tomados em seu conjunto, eles constituem nossas 'culturas'. Contribuem para assegurar que toda ação social é 'cultural', que todas as práticas sociais expressam ou comunicam um significado e, neste sentido, são práticas de significação.
\end{abstract}

Dessa maneira, reconhecemos que as vivências e sentidos partilhados pelos sujeitos na vida em sociedade são determinantes em seu processo de humanização. Isso inclui as experiências familiares e também aquelas vividas em outras instituições sociais e espaços-tempos, incluindo a escola.

Neste trabalho, damos especial atenção ao processo de humanização que acontece na infância, mediado pela educação. A cultura infantil é compreendida por Brougère (2010) como o conjunto de significados partilhados pelas crianças, especialmente aqueles voltados às brincadeiras, e que são fruto da influência da cultura adulta, da mídia, mas passam pela reinterpretação, reelaboração dos sujeitos infantis, constituindo modos bastante próprios de viver a infância e apropriar-se do mundo. Nesse 
universo, a arte assume lugar privilegiado, pois aciona os sentidos, convoca o corpo inteiro.

Concordamos que a arte e sua dimensão poético-formativa fazem com que "[...] a intencionalidade educativa de tornar o mundo mais humano possa coexistir com a intencionalidade de sonhar e pensar um humano mais mundano" (RICHTER, 2016, p. 90). Nossa constituição, enquanto sujeitos, se faz na vida pulsante, na relação com a cultura, na inseparabilidade dos sentidos e ação de um corpo sensível, bastante presente no existir das crianças. $O$ modo com o qual as crianças subvertem muitos pressupostos escolares, por meio da curiosidade, do viver o corpo no encontro entre a ludicidade e a lucidez, entre a fantasia e a realidade, leva a brincadeira, a imitação e a criação para o centro das ações pedagógicas (RICHTER, 2016).

Neste aspecto, para Cunha (2018) a arte tem estreita relação com o modo de construção de saberes das crianças, as quais fazem maior uso de processos criativos em suas brincadeiras e formas de interação e apropriação do mundo. Isso porque as possibilidades expressivas e artísticas das crianças acontecem em fluxo contínuo e desconhecem limites.

As crianças são curiosas, brincantes, com capacidade para se maravilhar com o mundo e com seus sons e silêncios, entonações e modulações da fala, com cores, formas, luzes, objetos, movimentos, deslocamentos, modos variados de ocupação de tempos e de espaços, e atuam a partir de um corpo que se arrisca com paixão a essas descobertas e experimentações (CUNHA, 2018, p. 237).

A reflexão da autora se associa ao que entendemos pelo binômio corpo-criança, isto é, sujeito infantil cujo corpo está visceralmente implicado nos seus modos de ser e estar no mundo, nas suas aventuras, descobertas e vivências. Um corpo vivo, pulsante, curioso, que se envolve nas descobertas, transgride, "desobedece", não se acomoda à linearidade da vida social, geralmente regrada, disciplinadora e controladora.

Cabe registrar que os sentidos e comportamentos corporais, como os signos que integram as letras e os números, são aprendidos. Nossas formas de ser corpo no mundo dependem dos processos educativos que experimentamos durante toda a vida (MAUSS, 2003; SOARES, 2002). A partir do exposto, podemos reconhecer que a arte e a educação têm em comum uma maneira de questionar o mundo que aciona reflexões pessoais, as quais precisam ser encorajadas e estimuladas. $O$ diálogo entre a arte e a educação do corpo podem representar uma forma de resistência contra os relatos únicos, "[...] que desfiguram a experiência subjetiva e sensível [...]" (SOARES; MADUREIRA, 2005, p. 86), desde que valorize o diverso, o diferente, abra espaço para o pensar e agir divergentes.

[...] acreditamos ser necessário transbordar as poéticas do cotidiano que permeiam a pedagogia da infância na educação infantil e contaminar a escola fundamental com a didática da maravilha. A docência na creche, na pré-escola e nos anos iniciais do Ensino Fundamental podem ser aliadas nesse processo e a arte ser a grande aglutinadora de encontros poéticos, políticos e pedagógicos que garantam o direito 
pleno à infância e à educação (RICHTER; SILVA; FARIA, 20I7, p. 248).

Richter, Silva e Faria (2017), assim como Marques (2003), chamam a atenção para a necessidade de educar as crianças para além do cognitivismo reinante e dar lugar ao corpo sensível e linguageiro, reconhecendo a arte em sua potência de aglutinar encontros poéticos que garantam o direito pleno à infância e à educação. As primeiras autoras, ao replicar uma carta dos direitos das crianças à arte e à cultura, destacam a importância de experimentar linguagens artísticas que desenvolvam a inteligência corporal, de participar de processos artísticos que nutram sua inteligência emotiva.

As crianças são iniciantes na vida e na arte, e o mundo, para elas, é fascinante pelo que ele lhes oferece em termos de descobertas, de vivências e suas consequentes aprendizagens, que elas expressam por meio de linguagens mais afeitas às características infantis. Estas englobam as sonoridades todas, para além do que se ouve e fala, do que se vê, do que se move, do que se sente e intui, o que ainda não existe e pode ser criado (CUNHA, 2018, p. 242-243).

Albano (20l8) nos faz o intrigante questionamento sobre qual arte educa, qual é levada à escola pelos professores e aquela que entra sem sua participação pelos livros didáticos. Destaca que a arte precisa impressionar, levar ao desconhecido e desse modo pode educar, preservando o espaço da fantasia e com lugar para a expressividade: "Se entrar na escola para causar confusão criativa, para provocar questionamentos, para levar à consciência de que existe um mundo de possibilidades a serem descobertas, estará cumprindo seu papel” (ALBANO, 2018, p. 15-16).

Dessa forma, a arte enquanto expressão tem um fim em si mesma e serve à fruição, atendendo às necessidades estéticas. Mas também, como educação, ela é instrumento para a formação de sujeitos expressivos, críticos e conscientes de sua condição ativa nos processos de criação das diferentes formas de sociabilidade: "[...] a arte é necessária para que o homem se torne capaz de conhecer e mudar o mundo. Mas a arte também é necessária em virtude da magia que lhe é inerente" (FISCHER, 1983, p. 20).

O que se observa, a partir das definições apresentadas, é que a elaboração e a fruição da obra de arte são processos que atravessam permanentemente a dimensão corporal: para dar forma à subjetividade, o artista domina as técnicas do corpo para pintar, esculpir, encenar, ouvir e compor melodias, entre outras (SOARES; MADUREIRA, 2005). Da mesma forma, a fruição de uma obra de arte perpassa os sentidos. Em ambas as situações, o corpo se apresenta como instrumento, "[...] o corpo é o primeiro e o mais natural instrumento do homem" (MAUSS, 2003, p. 407), seja para produzir, seja para apreciar a obra de arte:

A arte é sempre uma expressão do corpo. Sua matéria, seu ponto de partida e de chegada é sempre o corpo. Às vezes a matéria-corpo aparece de forma oculta, traduzida em tintas, palavras ou acordes musicais. Ainda assim, é a experiência 
humana encarnada que se revela em terrores e júbilos (SOARES; MADUREIRA, 2005, p. 75).

A música "O caroço da cabeça", composição de Marcelo Fromer, Nando Reis e Herbert Vianna, e lançada pelos Titãs em 1995, é uma bela referência para essa discussão. Nela, os compositores comparam os órgãos dos sentidos com instrumentos/ferramentas criadas pelo ser humano justamente ao longo de um processo de busca pelo não movimento. As técnicas corporais de que nos fala Mauss (2003) vêm sendo potencializadas e, em muitos casos, substituídas ao longo da história humana por ferramentas e máquinas.

Para ver os olhos vão de bicicleta até enxergar Para ouvir as orelhas dão os talheres de escutar Para dizer os lábios são duas almofadas de falar Para sentir as narinas não viram chaminés sem respirar Para ir as pernas estão no automóvel sem andar

E o que é que ainda estão fazendo as crianças dentro do colégio? Já que o sol está brilhando como nunca do lado de fora da sala de aula E há uma única pétala vermelha na haste dessa rosa que continua bela, gritando...

$E$ os ossos serão nossas sementes sob o chão $E$ dos ossos as novas sementes que virão. ${ }^{6}$

Se no processo produtivo, a ação corporal está se tornando cada vez mais obsoleta, o mesmo não se pode dizer sobre as nossas formas de apreender o mundo por meio dos sentidos e das experiências corporais. Arroyo e Silva (20I2) compartilham reflexões sobre o tenso exercício de ser criança e nos convocam a pensar em outras pedagogias dos corpos. Para eles, os corpos e a infância se revelam como expressão do humano, diverso, desigual, interrogam nosso olhar e nossas práticas educativas. Arroyo (2012) ressalta que a pedagogia e a docência não podem mais ignorar os corpos infantis na especificidade das experiências sociais, na tentativa de recuperar a humanidade roubada das crianças.

Nesse sentido, a música "O Caroço da Cabeça", apresentada anteriormente, chama a atenção para os processos educativos restritos à sala de aula: enquanto o sol brilha e "[...] uma única pétala vermelha na haste dessa rosa continua bela, gritando [...]" para ser apreciada, para que as crianças aprendam, por meio dos sentidos, o encantamento com o mundo. Pelo contrário, um olhar atento à escola e, em especial, à escola dos pequenos, reflete a busca por reprodução e uniformidade, por meio de um conjunto de normas extremamente limitantes de ação corporal: em sala de aula os alunos sentam, de preferência com uma postura correta, em cadeiras padronizadas, apoiam os braços e

\footnotetext{
6 'O caroço da cabeça', ["O caroço da cabeça”] música de Marcelo Fromer, Nando Reis e Herbert Vianna, lançada pelos Titãs em 1995 no álbum "Domingo". [Domingo].
} 
escrevem sobre as mesas, olhando para frente, em silêncio (STRAZZACAPPA, 200I). A rotina escolar se inicia com a fila, muitas vezes com as mãos para trás ou os braços ao longo do corpo, e o silêncio que acompanha o passo a passo para a sala de aula. Em sua pesquisa, Santos (2020, p. 61) discute que:

A fila nas instituições educativas é adotada sob o argumento da organização, entretanto, acaba por conformar os corpos a uma vivência extremamente controlada, associada a sanções caso haja descumprimento. Foi perceptível a dificuldade das crianças em ajustar os corpos para andar com as mãos para trás, exigindo deles equilíbrio e contenção de movimentos. Em diversas situações presenciamos tropeços [...].

Entre as atividades desenvolvidas para/pelas crianças privilegia-se a imobilidade, desenhos (já semiprontos) no papel, ouvir histórias com raras oportunidades de interferência, sentadas e caladas.

Todos os papéis são sempre do mesmo tamanho, do mesmo formato, da mesma cor. Os temas são os mesmos para todos, sem distinção. Mas os desejos das crianças não cabem, necessariamente, no mesmo tamanho do papel $A 4$, nem podem ser expressos com as mesmas cores. Parece-me que os professores ignoram que a arte pertence, essencialmente, ao campo do desconhecido, da imaginação, do sonho, onde todas as diferenças se manifestam. Não há sonho igual a outro, nem da mesma cor e tamanho (ALBANO, 2018, p. 13).

Mesmo nos momentos de movimento, como as aulas de Educação Física e o recreio, a estrutura da escola e a vigilância permanente parecem cercear o viver corporal espontâneo e criativo, com a reprodução de gestos padronizados, o controle sobre os usos do espaço, os constantes pedidos de "silêncio", “não corra”, “não grite”, "senta ai" (STRAZZACAPPA, 200I; SANTOS, 2020).

Tal contexto explicita a organização escolar etapista, sequencial, enrijecida para os corpos-vida na infância, exigindo que repensemos as estruturas espaço-temporais de trabalho e aprendizagem. Assim, seja no âmbito escolar institucionalizado ou por outras vias sociais, sobram tratos antipedagógicos dos corpos como forma de silenciar as presenças incômodas, as manifestações corpóreas explosivas (ARROYO, 20I2).

Mas, a arte não é apenas submissão àquilo que a sociedade determina. Ela também é potência, é subversão, é possibilidade. Como afirma Fischer (1983), a arte permite a cada indivíduo incorporar tudo aquilo que não é como indivíduo, mas poderia ser como gênero humano. Tem como característica central o trabalho criador. $O$ artista expressa a realidade a partir da sua forma singular de apreendêla, como sujeito histórico condicionado ao espaço-tempo, mas também como membro da espécie humana que traz consigo certo potencial de transcendência. A obra de arte carrega consigo elementos da singularidade histórica, mas também expressa elementos da universalidade humana.

A expressão de possibilidades de criação se concretiza nos gestos, nos movimentos no espaçotempo, sendo o corpo das crianças, suas brincadeiras, exercícios de modos de viver e habitar o mundo, se relacionar com o outro, como pontua Cunha (2018, p. 245-246): 
O corpo todo, em suas sensações, em seus movimentos e deslocamentos pelos espaços, em grandes e pequenos gestos, se lança às pesquisas de modos de atuar e de ser, às repetições e insistências ao lidar com as características constitutivas das materialidades de diversas naturezas, reordenando-as de acordo com novos sentidos, que devem ser estabelecidos pelo interesse das crianças, a estética das crianças, e não pelas expectativas adultas [...].

Nesse aspecto, as práticas corporais circenses se destacam como espaço de inventividade. Luigi Pareyson (200I, p. 25-26) denomina o trabalho do artista de formatividade. Segundo ele, ao mesmo tempo que faz arte, o artista inventa o modo de fazer:

O fato é que a arte não é somente executar, produzir, realizar, e o simples 'fazer' não basta para definir sua essência. A arte é também invenção. Ela não é execução de qualquer coisa já ideada, realização de um projeto, produção segundo regras dadas ou predisposta. Ele é um tal fazer que, enquanto faz, inventa o por fazer e o modo de fazer.

Assim, fazer circo é, também, inventar modos de fazer circo. E, sendo o corpo o seu principal artista, então este fazer é também inventar modos de ser corpo, para além dos padrões limitantes socialmente impostos. Historicamente, os corpos circenses têm mostrado seu potencial para transgredir, questionar, criticar o que está posto (BOLOGNESI, 200I). São corpos de um agir divergente, aqueles que não se acomodam nos mesmos movimentos, que "desobedecem" a normatividade, resistem, criam. Podemos dizer que as práticas circenses com as crianças proporcionam a vivência da corporeidade para além da conformidade dos movimentos que convergem, são iguais, na medida em que possibilitam criação, interação.

A arte popular da Idade Média, por exemplo, se utiliza de elementos cômicos e da linguagem circense para expressar as contradições de sua época. Se a organização social dominante estava interessada em manter privilégios e posições hierárquicas, tal ideologia estava presente no corpo coisificado da arte elitista, que elevava, ao nível das ideias, tudo o que segundo a elite era central, puro e superior: "[...] é um corpo perfeitamente pronto, acabado, rigorosamente delimitado, fechado mostrado do exterior, sem mistura, individual e expressivo" (BAKHTIN, 20I3, p. 279).

Mas a arte popular inventou um outro corpo, exposto, inacabado, incompleto, transmutável, criador de novos modos de vida e organização, o corpo grotesco, que se mostrou palco de resistência aos ditames das elites, espaço para o contraditório, sátira aos costumes da nobreza e às crenças religiosas. A corporificação da vida torna-se elemento de transgressão. Para Bakhtin (2013), os orifícios e prolongamentos corporais no realismo grotesco representam mecanismos de interação com o mundo. O corpo gigante é desproporcional, desajustado ao espaço que ocupa. "No realismo grotesco [...] o princípio material e corporal aparece sob a forma universal, festiva e utópica. O cósmico, o social e o corporal estão ligados indissoluvelmente numa totalidade viva e indivisível. [...]" (BAKHTIN, 20I3, p. 17). 
Estes elementos estão presentes na teatralidade dos palhaços até hoje. O corpo do palhaço é um corpo desajustado, atrapalhado, seus pés são desproporcionais, seu nariz é grande, redondo e vermelho, ele tropeça em seus próprios sapatos ao caminhar e, se para alguns essa configuração é motivo de riso, para muitos provoca repulsa. $O$ palhaço brinca com as fragilidades humanas, ele trabalha com o erro e expõe aquilo que nos esforçamos para esconder. Temos medo de perder, de fracassar, de parecer idiotas, ser objeto de riso. Todas as coisas que morremos de medo de que os outros pensem a respeito de nós constituem o lugar onde o palhaço constrói: "Há uma positividade no erro. O erro não atrapalha ou destrói, mas cria. Uma coisa que não dá certo, pode ser também a oportunidade do surgimento de outra, talvez até então impensada, de transformar as coisas" (KASPER, 2004, p. 63).

Da mesma forma, o corpo treinado do acrobata se mostrou contrário aos ditames da sociedade industrial do século XIX. Num tempo em que a atenção da ciência estava em desenvolver tecnologias que permitissem ampliar a produção fabril, orientando mecanicamente a força para a economia, para o melhor desempenho, eficiência (HEROLD JR., 20I2), os acrobatas dispendiam forças desmedidas sem gerar trabalho útil. Ainda, disseminavam a fantasia e a possibilidade de realizar o impossível quando voavam em seus trapézios; desdenhavam da gravidade em um estreito arame há muitos metros do chão, e "Exibiam o que se desejava ocultar e despertavam imagens adormecidas no coração dos homens" (SOARES, 2002, p. 28). Esses mesmos corpos cômicos e acrobatas movimentaram a Revolução Proletária na Rússia, como importantes instrumentos de comunicação com as massas populares para a disseminação dos ideais socialistas (BOLOGNESI, 20I0).

Assim, temos nos corpos circenses e suas técnicas a oportunidade de experimentar a dissonância. Ancorados na perspectiva de Gallo (2015, p. 342), concordamos que, de certo modo, as crianças envoltas nessas práticas materializam a possibilidade de resistência: "[...] o ingovernável; o ineducável; o que fica; o que não passa. O que em nós, resiste e insiste".

\section{Corpos circenses e a educação: experiências estético-formativas na infância}

A seguir, apresentamos algumas experiências realizadas pelo projeto de extensão "Circo em Contextos", em diálogo com a literatura acadêmica da área. As informações utilizadas para nossas análises têm como fonte o Relatório Final do projeto de extensão (UNICENTRO, 202I). As falas estão identificadas com nomes fictícios e idade dos participantes, sendo diferenciadas das demais citações do texto pela utilização do recurso itálico.

A reflexão sobre o entrelaçamento entre educação, arte e formação humana problematiza a necessidade de aproveitar os processos criativos da criança, valorizar o pensamento divergente que se impõe ao desejo da convergência o qual busca ações, trabalhos, movimentos iguais. 
Considerando a importante relação entre educação e arte, Cunha (2018) nos inspira a perguntar: $\circ$ que captura $\circ$ interesse das crianças, $\circ$ que as move a produções artísticas das quais efetivamente participam e lhes sejam significativas? Entre as diversas respostas possíveis apresentamse as atividades circenses, pois estão integradas à cultura da infância, com elementos próximos ao viver infantil, incorporam um sentido estético. Ajudam as crianças a construir suas próprias narrativas, suas formas de pensar e estar no mundo que subvertem gestualidades ritmadas, corpos controlados, produções que valorizam a cópia e o modelo e se configuram como processos abertos que valorizam a experiência.

Está inscrito no corpo o encontro entre a criança e o circo, nas múltiplas possibilidades de se movimentar, experimentar os sentidos, viver a fantasia de mundos inventados. Nas palavras do artista e historiador circense Antônio Torres: "O destino errante seduz tanto quanto a magia de seus espetáculos. Atrás do circo vai o fantástico show da vida, arrastando um contingente em fuga da sensaboria de noites sempre iguais. Para onde a lona for, vai um sonho" (TORRES, 1998, p. 24). Cabe ilustrar o encantamento despertado pelo circo quando uma das crianças do projeto explicou por que gostava de participar:

Eu gosto de vir aqui! Ah, porque é circo né! (Pedro, 6 anos, UNICENTRO, 202I).

A fala de Pedro expressa o entendimento de que não há necessidade de maiores esclarecimentos para a pergunta, um tanto óbvia para ele. Pareceu estar na essência do circo ser divertido e atraente para uma criança.

O projeto de extensão "Circo em Contextos" é desenvolvido na Universidade Estadual do Centro-Oeste, campus Irati, Paraná, desde o ano de 201 I (TREVIZAN; CHAGAS; KRONBAUER, 2018). Tem o objetivo de oportunizar espaços para a experimentação com as práticas corporais circenses para a comunidade, bem como fomentar o seu ensino na escola, por meio da formação de professores. Os relatos que ora apresentamos se referem às oficinas de práticas corporais circenses para crianças, realizadas durante o ano de 2019, as quais aconteceram em duas modalidades. A primeira delas, de maneira permanente, aconteceu em encontros semanais de uma hora com um grupo de aproximadamente 70 crianças e frequência semanal média de 50 crianças entre 4 e 12 anos de idade. A segunda modalidade consistiu de oficinas isoladas de duas horas de duração, com participação de grupos de 40-50 crianças das escolas da região, conforme agendamento, e atendeu aproximadamente 260 crianças. A equipe executora do projeto foi composta de uma professora coordenadora (uma das autoras deste artigo), uma professora de Educação Física e diversos monitores, entre bolsistas e voluntários, dos cursos de Educação Física e História.

Em ambos os casos, as atividades das oficinas aconteceram no Pavilhão Didático da 
universidade. A cada dia, as crianças eram organizadas em grupos de 10-15; algumas vezes por critério de faixa etária; outras por vínculos já estabelecidos entre elas; e outras por sorteio. Mesmo assim, procuramos manter pelo menos dois ou três amigos no mesmo grupo. A partir dessa dinâmica, foi possível observar a ampliação das relações sociais entre as crianças, pois havia uma referência de amizade e, ao mesmo tempo, a necessidade de conviver com outras.

As oficinas ocorreram em forma de circuito de três, quatro ou cinco estações, com diferentes atividades, conforme o número de participantes do dia. Cada estação era coordenada por dois ou três monitores. Os grupos de crianças permaneciam em torno de 15-20 minutos em cada estação nas oficinas permanentes, e 30 minutos nas oficinas isoladas.

A maioria das atividades foi adaptada de obras, como as de Bortoleto (2008; 2010), Bortoleto, Pinheiro e Prodócimo (20I I) e dos e-books desenvolvidos para a disciplina de Atividades Circenses na Escola (KRONBAUER, 20I8) e Manifestações Corporais Expressivas (KRONBAUER, 2019) do curso de Licenciatura em Educação Física da universidade. Entre as atividades realizadas podemos citar: acrobacias aéreas no tecido, na lira e no trapézio; acrobacias de solo individuais como rolamento para frente, para trás, "elefantinho" (parada de três apoios), parada de mãos; acrobacias coletivas como pirâmides diversas; jogos de malabares com bolas, tecidos, e outros materiais com diferentes pesos, formas, tamanhos e texturas; equilíbrio sobre barras, cordas, pneus; jogos rítmicos com música, copos, palmas, partes do corpo; jogos expressivos com ênfase para a linguagem não verbal ${ }^{7}$.

No que se refere ao método de ensino, pautamo-nos nas ideias de experimentação e segurança. As crianças recebiam orientações criteriosas sobre a sua segurança e a dos colegas, o respeito e o cuidado com o seu corpo e com o corpo do outro. Essas questões foram fundamentais, principalmente nos equipamentos aéreos e naqueles que envolviam $\circ$ contato com $\circ$ colega (BORTOLETO, 2008; 2010). Durante muitos movimentos, como a parada de mãos, por exemplo, as crianças eram ensinadas a dar apoio aos colegas. Ao montar uma pirâmide humana, era preciso chamar a atenção para o peso a ser sobreposto ao corpo de outra criança, como segurar, como se posicionar, sem machucar os colegas, oportunizando um reconhecer de si e do outro.

Para além das orientações de cuidado e segurança, as crianças eram estimuladas a descobrir formas de realizar os movimentos e tarefas. Podemos destacar alguns exemplos dos desafios propostos: como se deslocar pelo tatame sem usar os pés como apoio? Como segurar, jogar, capturar um objeto sem usar as mãos? Como carregar um colega de um lugar para outro, sem machucar? Como

7 Os materiais didáticos utilizados estão disponíveis para consulta no site do projeto: https://circoemcontextos.wixsite.com/circo 
apoiar seu corpo suspenso no tecido? Como sentar no trapézio sem alcançar os pés no chão para impulsionar a subida? Como saltar diferente do meu colega? Como se posicionar nos diferentes equipamentos, para enxergar o mundo de cabeça para baixo? Como fazer música sem instrumentos musicais? Como acompanhar o ritmo de uma música com diferentes gestos? Como expressar uma dor de barriga, a saudade, o entusiasmo, sem falar?

As experimentações promoveram uma variedade de manifestações e interpretações, novos olhares, formas de se expressar que vão além da palavra, convocam o corpo todo, as emoções e os sentimentos. As crianças falam com os adultos de muitas formas, com olhares, vocalizações, resistências, silêncios e precisamos estar dispostos e vigilantes a observar e escutar suas manifestações.

Tais desafios levam em consideração a inquietude, a doação, o espírito aventureiro, o riso solto, o corpo ligeiro das crianças, que é sensível aos cheiros, cores, sons, movimentos das coisas. Esse encantamento sensível que as crianças têm com o mundo faz do circo um universo favorável para o despertar dos sentidos: "Estar envolvido implica estar tomado pelo acontecimento. Só aprendemos quando estamos por inteiro naquilo que fazemos" (RICHTER; SILVA; FARIA, 20I7, p. 242).

Em contextos favoráveis, as crianças estabelecem com facilidade e fluência associação com a dimensão poética, pela forma como interrogam o mundo e o decifram, ou seja, infância e arte são solidárias no movimento de abertura à vida (RICHTER; SILVA; FARIA, 20I7). Cabe citarmos aqui o depoimento de uma das crianças que participou das oficinas no ano de 2019 e continuou realizando algumas atividades em casa no ano de 2020:

Eu gostei muito das aulas de circo, estou com muita saudade. Na pandemia fiquei em casa treinando o malabarismo com as bolas de arroz. (Henrique, 6 anos, UNICENTRO, 202I).

No circo, os encontros entre o risco e o riso, o sublime e o grotesco, a fantasia, a linguagem artística circense acontecem pela via corporal. Assim, as perguntas e os desafios propostos nas oficinas possibilitaram que as crianças realizassem as atividades explorando suas potencialidades corporais e o processo de se construir corpo.

Em sequência às primeiras descobertas, ensinamos posturas e gestos específicos de cada modalidade circense. A tentativa de imitação, neste caso, se torna também um importante elemento no processo de aprendizagem dos comportamentos corporais (MAUSS, 2003), que acontece na intersecção entre um gesto de referência e as condições singulares de cada corpo. Diferentemente da técnica esportiva, que oferece padrões biomecânicos que permitem maior eficiência no gesto e, consequentemente, melhores resultados, as experiências com as práticas corporais circenses nas oficinas permitiram que as crianças descobrissem suas próprias estratégias. 
Aqui, aprender não diz respeito a processos cumulativos do percebido, mas à metamorfose do corpo em abertura para a experiência temporal de começar-se. Convém destacar que o processo da metamorfose é delicado, pois implica mudança radical no corpo sem a sua perda ou destruição: todo o ser transforma-se mantendose, conservando-se. Processo temporal, histórico, sempre inacabado pelo movimento do corpo em sua conquista de outros movimentos (RICHTER; SILVA; FARIA, 2017, p. 243).

Dá-se o diálogo entre a possibilidade de criação do novo e a garantia de acesso aos conhecimentos corporais sistematizados e expressos na linguagem circense ao longo de sua história. As oficinas se consolidaram como espaço para o criar e o desenvolver de formas singulares de viver o corpo, por meio de uma manifestação corporal artística, e, ao mesmo tempo, oportunizaram às crianças conhecer a cultura circense. As falas a seguir expressam alguns aprendizados proporcionados pelo projeto:

É bem legal. Porque a gente faz várias coisas e aprende coisas novas. Eu fui no trapézio, eu fiz malabarismo, cambalhota. (Cora, 9 anos, UNICENTRO, 202I).

Eu gosto de vir aqui... porque tem aquele lenço! (Vitória, 5 anos, UNICENTRO, 202I).

Eu aprendi o trapézio, aprendi o malabares, aprendi a estrelinha. (Júlia, 6 anos, UNICENTRO, 202I).

Como entende Ostetto (2020), a intersecção entre arte, infância e educação pode promover reflexões e práticas potentes de contato significativo com a arte, em percursos poéticos sensíveis à experimentação e criação. Assim, recuperar o poder produtivo da imaginação e dos sentidos,

É reclamar o direito à experiência de maravilhamento - de uma alegria fascinada diante das primeiras admirações com a plasticidade do mundo que convocam o corpo da criança a "mexer-se" e lançar-se para encená-lo enquanto estratégia de um pensamento aderido ao mundo (RICHTER; SILVA; FARIA, 2017, p. 244).

Outra prática muito comum quando se trata de atividades artísticas direcionadas às crianças nas instituições educativas é a tradicional "apresentação de final de ano". Nesse momento, as famílias se reúnem e todas as experiências vivenciadas ao longo de um determinado período se resumem à performance de uma ou outra coreografia, uns "passinhos" de dança ou um "teatrinho" (STRAZZACAPPA, 200 I; MARQUES, 2003). Na lógica da produtividade, parece necessário confirmar que o investimento dos pais (principalmente no caso de atividades que necessitam de pagamento) obteve resultados satisfatórios.

Considerando que a proposta pedagógica do projeto se concentra em oportunizar experiências de movimento, não "ensaiamos" nenhuma apresentação de final de ano. Como encerramento das atividades, as mães, os pais, avós e avôs, irmãs, irmãos, aqueles que cuidavam e traziam as crianças para as oficinas (vamos chamar de "amigos"), foram convidados a participar. 
Seguindo a mesma organização das oficinas, em grupos e circuitos de atividades, os "amigos" assumiram o papel de alunos, e as crianças foram desafiadas a serem seus professores, provocando o que Ostetto (2020) chama de desabituar os sentidos, dispondo-se a entrar na brincadeira nesse espaço de experimentação.

Entendemos que esse momento materializou a síntese das aprendizagens e experiências corporais. O protagonismo das crianças em ensinar seus "amigos" exigiu delas, ao mesmo tempo, mostrar corporalmente as técnicas circenses, se comunicar e interagir, em um tempo compartilhado de brincar e aprender com aqueles que estão mais próximos do seu cotidiano.

As crianças abordam o mundo e o desconhecido de modo diferente dos adultos: em sua inexperiência - outra temporalidade - o abordam encantadas, admiradas, espantadas, investigativas. Tal abordagem acontece no âmbito dos saberes sensíveis que emergem das raizes corporais: um saber primal, fundante, direto, anterior aos processos de raciocínio e reflexão, que exige o encontro com as qualidades do mundo. Sons, cores, sabores, texturas e odores nos colocam no mundo e são por nós corporalizados. Por provocar um excesso sensivel, uma relação direta, é preciso compartilhar a experiência. Compartilhar é estar junto em um tempo, é compartilhar um ritmo determinado, seus intervalos, suas ressonâncias e repercussões (RICHTER; SILVA; FARIA, 20I7, p. 24I).

Por outro lado, este "aulão" de circo evitou o enfrentamento com uma plateia que pode, por vezes, se apresentar como um ambiente pouco acolhedor das diversidades. A exposição do palco pode gerar julgamentos que embaraçam e oprimem as corporeidades singulares. Os corpos infantis, assim como os corpos circenses, nem sempre se encaixam em padrões pré-estabelecidos, pois desafiam o mundo e criam suas próprias referências, sendo nosso papel desenvolver propostas potentes "[...] que tomem como ponto de partida o protagonismo das crianças em seus peculiares modos de habitar o mundo" (CUNHA; CARVALHO, 2020, p. I3). Relatou-nos uma das mães que participou das atividades:

A Beatriz é uma criança bem tímida. $E$ as aulas de circo ajudaram ela adquirir maior confiança. Nas primeiras aulas ela ficava encolhida mais observando e no último dia em que foi aberto para a familia participar, ela realizou os exercícios com desenvoltura e confiança. Isso influencia a forma da criança perceber o seu potencial para além das aulas de circo. (Ana, mãe, UNICENTRO, 202I).

A metodologia adotada e a condução das atividades, desde seu início até a finalização, tomou como mote a participação das crianças, seu posicionamento, promovendo experimentações, intercâmbios e construção de significados partilhados e vividos na coletividade. Num processo de mão dupla, observou-se o protagonismo e formação das crianças e os impactos na constituição profissional dos estudantes da equipe executora. As atividades circenses datam de longos anos e na contemporaneidade ainda são uma das possibilidades de criação artística e experiência estética para as crianças.

Em consonância com as Diretrizes para a Extensão na Educação Superior Brasileira (BRASIL, 
2018), o projeto assumiu o compromisso social de produzir e disseminar conhecimentos qualificados sobre as práticas corporais circenses e suas formas de ensino, integrando a formação de professores da Educação Básica e os sujeitos-foco dessa formação: as crianças. A interação entre universidade e comunidade estende a formação e o alcance do que é científico, articulando e considerando a realidade social, suas demandas e participação; fazendo ciência, pesquisa e produzindo conhecimento e formação para além dos muros da academia.

Experiências nessa direção ganham relevância num mundo dominado pela cultura abrangente dos meios de comunicação de massa, pelos interesses comerciais, cujas produções promovem um embotamento das subjetividades, uma formação superficial e caricaturizada. Resistir a essas condições, por meio de projetos artísticos que envolvam as crianças e os professores, representa uma importante forma de enfrentamento e formação humana.

\section{Considerações finais}

A relação entre educação, arte e infância foi objeto de reflexão e problematização neste texto, ilustrada nas ações de um projeto de extensão sobre práticas corporais circenses. Passando pelo universo das possibilidades e potencialidades, ao descrever algumas situações escolares expressas na literatura da área, constata-se que a educação tem restringido e formatado os corpos-criança, buscando o corpo-aluno. Os movimentos e experiências, nesse caso, privilegiam um agir convergente, em que fazer e pensar diferente não encontram morada.

As práticas pedagógicas propostas nas instituições educativas, via de regra, se pautam em ensinar a ouvir e olhar, antes do sentir, impõem uma pedagogia em seu generalizado desencanto pelo poder poético do corpo de inventar e multiplicar os sentidos e significados do mundo. A relação criança e corpo é construída nos espaços e tempos educativos com vistas à conformidade, do fazer e do pensar.

Tal condição nos convoca a reconhecer que, pelo contrário, a educação e sua dimensão estético-formativa precisam acolher a divergência, abandonando o treino de pensamentos e comportamentos iguais, estereotipados. O projeto apresentado configura-se como uma possibilidade de enfrentar esse engessamento dos corpos e dar lugar ao ser infantil, ao afeto, à criação, à partilha, aos olhares, escutas e diferentes perspectivas. As falas infantis revelaram como o projeto configurouse em oportunidade de acolhimento dos corpos-criança, do que os sujeitos pensam, criam e expressam, abrindo espaço para o pensar e o fazer divergentes, não resignados a normas e prescrições, mas abertos à experimentação, interação e criação.

Os corpos circenses são divergentes per se. O corpo treinado do acrobata utiliza quantidades 
desmedidas de energia corporal sem gerar trabalho útil, o que subverte a noção de eficiência ${ }^{8}$ presente nos processos produtivos modernos. O corpo do palhaço se constrói no erro, no atrapalho, na deselegância. O realismo grotesco tem no corpo a abertura para o diálogo com o mundo. $O$ teatro revolucionário do socialismo encontrou nos corpos circenses a expressividade para disseminar seus ideais, a energia e a criatividade para transformar as formas de organização do trabalho.

Quando compreendemos o corpo como instrumento da arte, e a arte como instrumento da educação do corpo, espera-se processos educativos que possibilitem espaços de criação e expressividade, permitindo a experimentação das mais variadas sensações, sentimentos e emoções. Essa concepção abre caminho para o pensar e o fazer divergentes, em que a estética do existir coloca os sujeitos como protagonistas, em que o corpo-criança encontra lugar.

Os corpos circenses comunicam-se e, consequentemente, educam a partir da singularidade limitadora e da potência universal, do devir: eles podem educar para a disseminação de ideais hegemônicos ou para a sua transgressão; para a submissão ou para a subversão; para a reprodução do estado das coisas ou para a possibilidade de transformação e criação de novas formas de sociabilidade. É possível a construção de uma outra realidade, que contempla, respeita e reconhece a diversidade de formas de ser corpo no mundo.

\section{Referências}

ALBANO, A. A. Agora eu era o herói: imaginação e expressão artística na primeira infância. Revista Digital do LAV, Santa Maria, v. II, n. 2, p. 9-19, maio/ago. 2018. Disponível em: https://doi.org// 0.5902/1983734833895. Acesso em: 06/0I/2I.

ARROYO, M. G. Corpos precarizados que interrogam nossa ética profissional. In: ARROYO, M. G.; SILVA, M. R. da (Org.). Corpo-infância: exercícios tensos de ser criança; por outras pedagogias dos corpos. Petrópolis: Vozes, 2012. p. 23-54.

ARROYO, M. G.; SILVA, M. R. da (Org.). Corpo-infância: exercícios tensos de ser criança; por outras pedagogias dos corpos. Petrópolis: Vozes, 2012.

BAKHTIN, M. Cultura Popular na Idade Média e no Renascimento: o contexto de François Rabelais. 8 ed. São Paulo: HUCITEC, 2013.

BOLOGNESI, M. F. O corpo como princípio. Trans/Form/Ação, São Paulo, 24, p. I0I-I I2, 200 I. Disponível em: https://doi.org/10.1590/S010I-31732001000100007. Acesso em: 08//2/20.

BOLOGNESI, M. F. Philip Astley e o Circo Moderno: romantismo, guerras e nacionalismo. $\mathbf{O}$ Percevejo, Rio de Janeiro, v. I, n. I, p. I-I3, 2009. Disponível em: http://www.seer.unirio.br/index.php/opercevejoonline/article/view/496/422. Acesso em: 10//2/20.

\footnotetext{
${ }^{8}$ A noção de eficiência, pautada nas teorias da mecânica, diz respeito à maior quantidade de trabalho produzido com menor quantidade de energia dispendida.
} 
BOLOGNESI, M. F. O Circo na história: a pluralidade circense e as revoluções francesa e soviética. Repertório - Teatro \& Dança, Salvador, ano 13, n. 15, p. II-16, 2010. Disponível em: https://doi.org/I0.977I/r.v0il5.5207. Acesso em: 19/0I/2I.

BORTOLETO, M. A. C. (Org). Introdução à Pedagogia das Atividades Circenses (Vol. I). Jundiaí, SP: Fontoura, 2008.

BORTOletO, M. A. C. (Org). Introdução à Pedagogia das Atividades Circenses (Vol. 2). Jundiaí, SP: Fontoura, 2010.

BORTOLETO, M. A. C., PINHEIRO, P. H. G. G; PRODOCIMO, E. Jogando com o circo. Jundiaí, SP: Fontoura, 20II.

BRASIL. Resolução CNE/CES N 7, de I 8 de dezembro de 20I8. Diretrizes Nacionais para a Extensão na Educação Superior Brasileira. Brasília: Ministério da Educação, 2018.

BROUGÈRE, G. Brinquedo e cultura. São Paulo: Cortez, 2010.

CUNHA, S. M da. Crianças fazendo arte: processos de criação artística e formação profissional docente para a Educação Infantil. Poiésis, Tubarão, v. I2, n. 2 I, p. 235-250, jan./jun. 20I8. Disponível em: http://www.portaldeperiodicos.unisul.br/index.php/Poiesis/article/view/5923. Acesso em: $06 / 01 / 21$.

CUNHA, S. R. V. da; CARVALHO, R. S. de. Sobre carrinhos, bagagens e viagens: diálogos entre artes plásticas, infância e pedagogia. CUNHA, S. R. V. da; CARVALHO, R. S. de (Orgs.). Arte contemporânea e educação infantil: crianças observando, descobrindo e criando. Porto Alegre: Mediação, 2020. p. 13-16.

FISCHER, E. A necessidade da arte. Rio de Janeiro: Zahar Editores, 1983.

GALLO, S. 'O pequeno cidadão': sobre a condução da infância em uma governamentalidade democrática. In: RESENDE, H. (Org.). Michel Foucault: o governo da infância. Belo Horizonte: Autêntica, 2015. p. 329-243.

HALL, S. A centralidade da cultura: notas sobre as revoluções culturais do nosso tempo. Educação \& Realidade, Porto Alegre, v. 22, n. 2, p. 15-46, jul./dez. 1997. Disponível em: https://seer.ufrgs.br/educacaoerealidade/article/view/7/36I. Acesso em: 19/0I/2I.

HEROLD JR. C. Corpo no trabalho e corpo pelo trabalho: perspectivas no estudo da corporalidade e da educação no capitalismo contemporâneo. Trabalho, Educação e Saúde, Rio de Janeiro, v. I0, n. I, p. II-35, mar./jun. 2012. Disponível em: https://doi.org/I0.1590/SI 98I-774620I 2000100002. Acesso em: 22/02/2I.

KASPER, K. M. Experimentações Clownescas: os palhaços e a criação de possibilidades de vida. (Tese de Doutorado). Programa de Pós-Graduação em Educação, Faculdade de Educação, Universidade Estadual de Campinas, 2004.

KRONBAUER, G. A. O circo como conteúdo da Educação Física na Educação Básica. Ebook. NEAD/UAB, UNICENTRO, 2018. Disponível em: https://0ed30f8e-b5I3-4805-a9b8879b2c9c6256.filesusr.com/ugd/28clc2_ef3d7f36c26d465aa4f420b5 I c3f2a5 I.pdf. Acesso em: $20 / 01 / 21$. 
KRONBAUER, G. A. Manifestações Corporais Expressivas e a Educação Física na escola. Ebook. NEAD/UAB, UNICENTRO, 2019. Disponível em: https://0ed30f8e-b513-4805-a9b8879b2c9c6256.filesusr.com/ugd/28clc2_1100b39a8fac40ce9590498d723fc9d8.pdf. Acesso em: $19 / 01 / 21$.

MARQUES, I. A. Dançando na Escola. São Paulo: Cortez, 2003.

MAUSS, M. As técnicas do corpo. In.: MAUSS, M. Sociologia e Antropologia. São Paulo: Cosac Naify, 2003. p. 40I-424.

OSTETTO, L. E. O encontro de gerações, as questões e proposições sobre arte e pedagogia na contemporaneidade. In: CUNHA, S. R. V. da; CARVALHO, R. S. de (Orgs.). Arte contemporânea e educação infantil: crianças observando, descobrindo e criando. Porto Alegre: Mediação, 2020. p. $9-12$.

PAREYSON, L. Os problemas da estética. São Paulo: Martins Fontes, $200 \mathrm{I}$.

RICHTER, S. R. S.; SILVA, A. A. da; FARIA, A. L. G. de. A educação encontra a arte: apontamentos político-pedagógicos sobre direitos e pequena infância. Zero a Seis, Florianópolis, v. 19, n. 36, p. 235-25I, jul./dez. 2017. Disponível em: https://doi.org/I0.5007//980-45I2.20 I7v/9n36p235. Acesso em: 06/0I/2I.

RICHTER, S. R. S. Educação, arte e infância: tensões filosóficas em torno do fenômeno poético.

Crítica Educativa, Sorocaba, v. 2, n. 2, p. 90-106, jul./dez. 2016. Disponível em: https://www.criticaeducativa.ufscar.br/index.php/criticaeducativa/article/view/99. Acesso em: $07 / 01 / 21$

SANTOS, A. C. R. F. dos; LIRA, A. C. M. Disciplinar e constranger: o corpo-criança e seu (não)lugar nas instituições educativas. Inter-Ação, Goiânia, v.45, n.3, p. 906-922, set./dez. 2020. Disponível em: https://www.revistas.ufg.br/interacao/article/view/64193. Acesso em: I7/0I/2I.

SANTOS, A. C. R. F. dos. Corporeidade infantil: quando o corpo-criança é transformado no corpo-aluno. Dissertação de Mestrado. Universidade Estadual do Centro-Oeste, Programa de PósGraduação em Educação, 2020.

SILVA, E. As múltiplas linguagens na teatralidade circense: Benjamin de Oliveira e o circoteatro no Brasil no final do século XIX e início do século XX. 2003. Tese (Doutorado em História). Departamento de História. Instituto de Filosofia e Ciências Humanas, Universidade Estadual de Campinas, Campinas, SP, 2003.

SOARES, C. L. Imagens da educação no corpo. Campinas: Autores Associados, 2002.

SOARES, C. L.; MADUREIRA, J. R. Educação Física, linguagem e arte: possibilidades de um diálogo poético do corpo. Movimento, Porto Alegre, v. I I, n. 2, p. 75-88, 2005. Disponível em: https://seer.ufrgs.br/Movimento/article/view/2869. Acesso em: 22/02/21.

STRAZZACAPPA, M. A Educação e a fábrica de corpos: a dança na escola. Cad. Cedes, Campinas, ano XXI, n. 53, p. 69-83, 200I. Disponível em: https://www.scielo.br/pdf/ccedes/v2 In53/a05v2I53.pdf. Acesso em: 19/0I/2I.

TORRES, A. O Circo no Brasil. Rio de Janeiro: FUNARTE; São Paulo: Atração Produções Ltda, 1998. 
TREVIZAN, M.; CHAGAS, P. I.; KRONBAUER, G. A. Circo em Contextos - diálogos entre a cultura e a extensão universitária. Revista Conexão UEPG, Ponta Grossa, v. I4, n. I, p. I30-139, 2018. Disponível em: https://www.redalyc.org/jatsRepo/5I4l/5/4161/59017/html/index.html. Acesso em: $22 / 02 / 21$.

UNICENTRO. Circo em Contextos (2019-202I). Relatório Final de Projeto de Extensão. Departamento de Educação Física, Setor de Ciências da Saúde, Universidade Estadual do CentroOeste, Unidade Universitária de Irati. UNICENTRO, 2021.

VEIGA-NETO, A. Cultura, culturas e educação. Revista Brasileira de Educação, Rio de Janeiro, n. 23, maio/jun./jul./ago. 2003. Disponível em: https://www.scielo.br/pdf/rbedu/n23/n23a0I.pdf. Acesso em: 19/0I/2I.

Recebido em: 04 de maio de 2021 .

Versão corrigida recebida em: 19 de abril de 2021 .

Aceito em: 27 de agosto de 2021.

Publicado online em: 04 de março de 2022. 